\section{Going antiviral in brain cancer}

\section{By Michael J. Haas, Senior Writer}

A Karolinska Institute-led team has shown that targeting cytomegalovirus and/or inhibiting COX-2 could help treat medulloblastoma, the most common type of pediatric brain tumor. ${ }^{1}$ The research presents a repurposing opportunity for companies with compounds against the virus or the enzyme.

Cytomegalovirus (CMV) infects a large proportion of the population-usually asymptomatically-and the virus expresses multiple proteins that allow it to escape the host immune response. ${ }^{2}$ The virus also infects more than $90 \%$ of glioblastoma, prostate, breast and colon tumors, ${ }^{3-5}$ in which it is thought to promote tumor growth and possibly tumorigenesis.

However, its role in cancer is poorly understood. ${ }^{6,7}$

Team coleader Cecilia Söderberg-Nauclér told SciBX her study was inspired by a report she heard on the radio about another Karolinska group-led by John Johnsen and Per Kogner-that showed cyclooxygenase-2 (COX-2) inhibition decreased the growth of neuroblastoma xenografts in rats. ${ }^{8}$

"When I heard this, I felt sure that CMV was involved in these tumors and controlling the expression of COX-2," said Söderberg-Nauclér, a professor of medical microbial pathogenesis in the Department of Medicine at Karolinska. The reason is her group had found that a high proportion of brain tumors were infected with CMV and had examined the virus' role in promoting inflammation.

Thus Söderberg-Nauclér teamed up with Johnsen and Kogner, who had also shown that COX-2 inhibition reduced the growth of medulloblastoma xenografts in mice, ${ }^{9}$ to investigate the potential connection between CMV and the proinflammatory enzyme COX-2 in medulloblastoma.

Johnsen is a senior investigator in the Division of Pediatric Oncology and Kogner is a professor of pediatric oncology in the Department of Women's and Children's Health at Karolinska division of pediatric oncology.

The team found that 8 of 8 human medulloblastoma cell lines expressed viral proteins from early and late in the CMV life cycle, as did more than $90 \%$ of primary medulloblastoma tumors. In the primary tumors, CMV status correlated with COX-2 expression.

Next, the group showed that the antiviral ganciclovir and the COX-2 inhibitor Celebrex celecoxib lowered the growth and proliferation of CMV-positive medulloblastoma cell lines but had no effect on CMVnegative prostate and pancreatic cancer cell lines. The team used these cell lines as controls because none of its medulloblastoma cell lines was CMV negative.

In mice with CMV-positive xenograft medulloblastomas, valganciclovir or Celebrex monotherapy decreased tumor growth by about $40 \%$, and the combination reduced tumor growth by $72 \%$, compared with no treatment. Neither drug affected tumor growth in CMV-negative prostate and pancreatic xenografts.

Pfizer Inc. and Astellas Pharma Inc. market Celebrex celecoxib to treat pain, rheumatoid arthritis (RA), osteoarthritis and other autoimmune indications. The drug is in Phase II/III testing to treat skin cancer and Phase II testing to treat lung cancer.

Roche markets the viral polymerase inhibitor Cytovene ganciclovir to treat CMV infection. Roche and Mitsubishi Tanabe Pharma Corp. market Valcyte valganciclovir, a prodrug of ganciclovir, to treat CMV infection.

Data were reported in The Journal of Clinical Investigation. ${ }^{1}$ The team included researchers from Lund University, the University Hospital of North Norway and the University of Tromsø.

"I think this is the first published study to show that inhibition of CMV replication can decrease tumor cell proliferation," said Charles Cobbs, a scientist at California Pacific Medical Center Research Institute and a neurosurgeon at the University of California, San Francisco. "This is a new finding in a major pediatric brain cancer that opens up a new paradigm for treating it."

Cobbs has received a grant from UCSF's Brain Tumor Specialized Program of Research Excellence (SPORE) to test antivirals other than valganciclovir in animals with glioblastoma xenografts. "We are also planning a clinical trial to test a new anti-CMV antiviral from an undisclosed company to treat glioblastoma," he said.

In 2002, Cobbs and colleagues reported that CMV infected a high proportion of malignant gliomal tumors and that the virus affected oncogenic cellular pathways. ${ }^{3}$

Cobbs said valganciclovir is probably not the best antiviral to target CMV in tumors because the drug only inhibits genes that are expressed in the intermediate and later stages of the virus' life cycle. "Genes expressed early in CMV's life cycle may also be important to its role in cancer," and the drug would have no effect on those, he said.

The results of the study "suggest not one but two potential new classes of drugs to add to oncologists' armamentarium" for brain cancer, said Francis Burrows, head of oncology biology at Tragara Pharmaceuticals Inc. "This is exciting work that makes a compelling case for the role of CMV in brain cancer by establishing a link between CMV infection of neural cells, activation of COX-2 and the development of medulloblastoma."

"Critics of the concept that CMV plays a role in cancer often argue that it is not surprising to find CMV in tumors when you can find it in many tissues throughout the body, at least temporarily," said Martin 
Michaelis, chair of cell biology at the University of Kent. "We think that data such as those presented in the JCI paper, which demonstrates that CMV affects the stage and prognosis of tumors and that the presence of the virus is associated with cellular expression of tumor-promoting genes like $C O X-2$, point in the right direction.”

\section{Combinations on the brain}

Burrows thinks the findings could make it worthwhile to run clinical trials of antivirals in combination with Tragara's Capoxigem apricoxib COX-2 inhibitor, although the company has not yet made plans to run such studies.

Tragara has Capoxigem in Phase II testing to treat non-small cell lung cancer (NSCLC) and pancreatic cancer.

Jindrich Cinatl Jr., professor at Goethe University's Institute of Medical Virology, said any clinical trials of an antiviral for brain cancer would help determine whether CMV's presence is relevant to cancer cell malignancy and tumor response to therapies.

Similarly, Burrows wanted to see experiments identifying the specific pathways and cell types that antivirals against CMV and COX-2 inhibitors targeted in brain cancers.

He said prior studies have suggested CMV and COX-2 drive a number of the hallmarks of cancer, such as inhibition of apoptosis, immune system evasion, angiogenesis and invasiveness. "It would be interesting to determine which oncogenic properties of CMV are mediated by COX-2" and thus know whether antivirals and COX-2 inhibitors were targeting the same or different pathways related to each of these cancer processes, he said.

Indeed, Michaelis said it was unclear from the JCI study whether ganciclovir was inhibiting viral replication or directly affecting viability in the medulloblastoma cell lines.

He noted that the Nordic researchers used ganciclovir concentrations of 37.5-150 $\mu \mathrm{m}$. "But a CMV-infected cell that has an $\mathrm{IC}_{50}$ greater than $12 \mu \mathrm{m}$ is considered ganciclovir resistant," he said. Such high concentrations "should not usually be needed to inhibit viral replication and may reduce the growth and viability of many different cell types, irrespective of their CMV status."

Michaelis also questioned whether the CMV-negative prostate and pancreatic cell lines were adequate controls. "It would have been better to establish CMV-negative medulloblastoma clones and investigate the effects of ganciclovir on the viability of those cell lines," he said.

Burrows wanted to know more about the potential connection between CMV and cancer stem cells.

He pointed to the team's results in one medulloblastoma cell line showing that some of the CMV-positive cells expressed prominin 1 (PROM1; CD133), which is thought to be a marker of cancer stem cells in glioblastoma multiforme (GBM), colon and several other tumors.

Those results suggest that "an interesting and potential vital aspect of the antitumor activity of antivirals against CMV and COX-2 inhibitors is their effect on cancer stem cells" in brain cancers, he said. If those agents do indeed target cancer stem cells, they could be combined with conventional radio- and chemotherapy to kill both the bulk tumor and tumor stem cells to prevent tumor recurrence.

Cobbs agreed. "If the virus is homing to tumor stem cells and driving their growth and proliferation, that would be a big deal," he said.

Söderberg-Nauclér said her team is investigating how-and at what stage of tumor development-CMV ends up in brain cells and the precise mechanisms by which the virus drives tumor growth and progression.

She acknowledged there is currently no evidence showing the virus actually causes brain cancer, but she told SciBX, "We definitely think $\mathrm{CMV}$ is closely linked to the development of cancer, given that we have found CMV in tumor cells that express stem cell markers and that such a high percentage of medulloblastoma cell lines and tumors are CMV positive. This can't just be coincidence."

Beyond the medulloblastoma work, her team has shown that CMV levels are a prognostic marker in GBM and has completed a Phase II trial of Valcyte in that indication. The marker data and trial results will be reported in separate upcoming publications, she said.

Söderberg-Nauclér declined to disclose the IP status of the findings reported in JCI but said the team is open to licensing or partnering opportunities.

Haas, M.J. SciBX 4(40); doi:10.1038/scibx.2011.1104

Published online Oct. 13, 2011

\section{REFERENCES}

1. Baryawno, N. et al. J. Clin. Invest.; published online Sept. 26, 2011; doi:10.1172/JCl57147

Contact: Cecilia Söderberg-Nauclér, Karolinska Institute, Stockholm, Sweden

e-mail: cecilia.naucler@ki.se

Contact: John Inge Johnsen, same affiliation as above e-mail: John.Inge.Johnsen@ki.se

2. Powers, C. et al. Curr. Top. Microbiol. Immunol. 325, 333-359 (2008)

3. Cobbs, C.S. et al. Cancer Res. 62, 3347-3350 (2002)

4. Harkins, L. et al. Lancet 360, 1557-1563 (2002)

5. Samanta, M. et al. J. Urol. 170, 998-1002 (2003)

6. Michaelis, M. et al. Med. Microbiol. Immunol. 198, 79-81 (2009)

7. Soroceanu, L. \& Cobbs, C.S. Virus Res. 157, 193-203 (2011)

8. Johnsen, J.I. et al. Cancer Res. 64, 7210-7215 (2004)

9. Baryawno, N. et al. Neuro. Oncol. 10, 661-674 (2008)

COMPANIES AND INSTITUTIONS MENTIONED

Astellas Pharma Inc. (Tokyo:4503), Tokyo, Japan

California Pacific Medical Center Research Institute,

San Francisco, Calif.

Goethe University, Frankfurt, Germany

Karolinska Institute, Stockholm, Sweden

Lund University, Lund, Sweden

Mitsubishi Tanabe Pharma Corp. (Tokyo:4508; Osaka:4508),

Osaka, Japan

Pfizer Inc. (NYSE:PFE), New York, N.Y.

Roche (SIX:ROG; OTCQX:RHHBY), Basel, Switzerland

Tragara Pharmaceuticals Inc., San Diego, Calif.

University of California, San Francisco, Calif.

University Hospital of North Norway, Troms $\varnothing$, Norway

University of Kent, Canterbury, U.K.

University of Tromsø, Tromsø, Norway 